\title{
Prognostic value of acute physiology and chronic health evaluation II score in post-operative of cardiac surgery
}

\author{
Valor pronóstico del sistema de calificación APACHE II en el postoperatorio de cirugía \\ cardíaca
}

\author{
Leonardo A. Seoane ${ }^{*}$, Juan Espinoza ${ }^{2}$, Lucrecia Burgos $^{3}$, Juan Furmento ${ }^{1}$, Luis Polero ${ }^{3}$, \\ Mariano Camporrotondo², Mariano Vrancic ${ }^{2}$, Daniel Navia², and Mariano Benzadón ${ }^{1}$ \\ ${ }^{1}$ Department of Cardiology, Critical Cardiology and Cardiovascular Recovery Section; ${ }^{2}$ Department of Cardiovascular Surgery; ${ }^{3}$ Department of \\ Cardiology, Instituto Cardiovascular de Buenos Aires (ICBA), Buenos Aires, Argentina
}

\begin{abstract}
Background and objectives: The Acute Physiology and Chronic Health Evaluation (APACHE II) score allows predicting in-hospital mortality in patients admitted to intensive care units. However, it is not validated for patients undergoing cardiac surgery, since it does not have a good discriminatory capacity in this clinical scenario. The aim of this study is to determine prognostic value of APACHE II score in post-operative of cardiac surgery. Materials and methods: The study was performed using the cardiac surgery database. Patients undergoing surgery between 2017 and 2018, with APACHE II score calculated at the admission were included. The receiver operating characteristic (ROC) curve was used to determine a cut-off value. The primary endpoint was in-hospital death. Secondary endpoints included low cardiac output (LCO), stroke, surgical bleeding, and dialysis requirement. A multivariable logistic regression model was developed to adjust to various variables of interest. Results: The study evaluated 559 patients undergoing cardiac surgery. The mean of APACHE II Score was 9.9 (standard deviations 4). The prevalence of in-hospital death was $6.1 \%$. The best prognostic cut-off value for the primary endpoint was 12, with a ROC curve of 0.92. Patients with an APACHE II score $\geq 12$ had significantly higher mortality, higher incidence of LCO, stroke, surgical bleeding, and dialysis requirement. In a multivariate logistic regression model, the APACHE II score was independently associated with higher in-hospital death (odds ratio, 1.14; 95 confidence interval \%, 1.08-1.21; $p<0.0001$ ). Conclusions: The APACHE II Score proved to be an independent predictor of in-hospital death in patients undergoing post-operative cardiac surgery, with a high capacity for discrimination.
\end{abstract}

Key words: Acute physiology and chronic health evaluation II score. Cardiac surgery. Risk scores.

\section{Resumen}

Antecedentes y objetivos: El sistema de calificación APACHE II permite predecir la mortalidad intrahospitalaria en terapia intensiva. Sin embargo, no está validado para cirugía cardíaca, ya que no posee buena capacidad diferenciadora. El objetivo es determinar el valor pronóstico de APACHE II en el postoperatorio de procedimientos cardíacos.

Correspondence:

*Leonardo A. Seoane

E-mail: laseoane@icba.com.ar
Date of reception: 25-09-2019

Date of acceptance: 16-04-2020

DOI: 10.24875/ACME.M20000148
Available online: 02-03-2021

Arch Cardiol Mex (Eng). 2020;90(4):363-370

www.archivoscardiologia.com 2604-7063 / C 2020 Instituto Nacional de Cardiología Ignacio Chávez. Published by Permanyer. This is an open access article under the CC BY-NC-ND license (http://creativecommons.org/licenses/by-nc-nd/4.0/). 
Materiales y métodos: Se analizó en forma retrospectiva la base de cirugía cardíaca. Se incluyó a pacientes intervenidos entre 2017 y 2018, de los cuales se calculó la puntuación APACHE II. Se utilizó curva ROC para determinar el mejor valor de corte. El punto final primario fue mortalidad intrahospitalaria. Como puntos finales secundarios se evaluó la incidencia de bajo gasto cardíaco (BGC), accidente cerebrovascular ( $A C V$ ), sangrado quirúrgico y necesidad de diálisis. Se realizó un modelo de regresión logístico multivariado para ajustar a las variables de interés. Resultados: Se analizó a 559 pacientes. La media del sistema de calificación APACHE II fue de 9.9 (DE 4). La prevalencia de mortalidad intrahospitalaria global fue de $6.1 \%$. El mejor valor de corte de la calificación para predecir mortalidad fue de 12, con un área bajo la curva ROC de 0.92. Los pacientes con APACHE II $\geq 12$ tuvieron significativamente mayor mortalidad, incidencia de BGC, ACV, sangrado quirúrgico y necesidad de diálisis. En un modelo multivariado, el sistema APACHE II se relacionó de modo independiente con mayor tasa de mortalidad intrahospitalaria (OR, 1.14; IC95\%, 1.08-1.21; $p<0.0001)$. Conclusiones: El sistema de clasificación APACHE II demostró ser un predictor independiente de mortalidad intrahospitalaria en pacientes que cursan el postoperatorio de cirugía cardíaca.

Palabras clave: APACHE II. Cirugía cardíaca. Calificaciones del riesgo.

\section{Introduction}

Currently, critically ill patients admitted to intensive care units show high in-hospital morbidity and mortality ${ }^{1,2}$. This may be due to the severity of the disease, the complexity of the operation or previous condition of the host, which may cause one or more organs' dysfunction during hospitalization ${ }^{1-3}$. Critically ill patients risk stratification is of great importance and has been the subject of study for several decades. Since 1970, different risk models have been used in intensive care units to predict in-hospital episodes. However, it is not clear which is the best rating system to determine the prognostic value of patients admitted to different types of critical care units (whether general, surgical or specific, such as cardiovascular recovery units, where patients who underwent cardiac interventions are exclusively assisted).

There are various models that enable predicting in-hospital mortality based on variables calculated upon admission to the intensive care unit. The Acute Physiology and Chronic Health Evaluation (APACHE) II, APACHE III, APACHE IV, the Simplified Acute Physiology Score (SAPS) II, SAPS III and the Mortality Probability Models II are some of the prognostic systems that are commonly used in the intensive care setting; in turn, the Sequential Organ Failure Assessment and the Multiple Organ Dysfunction Syndrome allow the evaluation of multiple organ dysfunction ${ }^{4-11}$. Most of them have been validated in general intensive care unit populations, and not in special therapy units or in certain subgroups of patients.

Subjects undergoing cardiac surgeries have been practically excluded from most works that have evaluated risk-grading models in critically ill patients. Cardiovascular recovery and cardiac surgery intensive care units serve a specific population, with characteristics of their own and unique. The pathophysiological consequences of the cardiopulmonary bypass pump modify, even if transiently, multiple variables that are commonly used by risk stratification rating systems in the immediate post-operative period. In addition, multiple physiological changes due to the use of devices such as intra-aortic counterpulsation balloon, hemofiltration, mechanical ventilation, and ventricular assistance have been observed, which make stratification difficult with common risk models ${ }^{12}$.

For this reason, in the field of cardiac surgery, the main parameters currently used for surgical risk rating are the EuroSCORE II and the Society of Thoracic Surgeons (STS) score ${ }^{13,14}$. Although these are valuable and validated models to predict morbidity and mortality in patients undergoing heart surgery, both use pre-operatively evaluated variables. Therefore, they do not consider various immediate intraoperative or post-operative factors of relevance, which are decisive for patient prognosis.

Regarding cardiac surgery post-operative biomarkers, there are common predictors with prognostic value, such as lactic acid and oxygen venous saturation. In spite of being good indicators of tissue hypoperfusion that allow therapeutics to be guided, they cannot predict actual patient risk in an isolated manner ${ }^{15-20}$.

In relation to risk-rating systems used in critically ill patients, APACHE II remains the gold standard for predicting in-hospital mortality in intensive care units, since it possesses broad evidence in critical and surgical medical units, is simple to calculate, is based on physiological variables, has been used for more than 30 years and has been validated in multiple cohorts from different countries, with good capacity for differentiation in the different clinical scenarios where it has 
been evaluated ${ }^{4,21-27}$. However, owing to calculated risk overestimation, it has not been validated in post-cardiac surgery patients.

The main purpose of the study was to determine the APACHE II scoring system prognostic value in individuals who are in the post-operative period of cardiac surgery in an high-complexity cardiovascular center.

\section{Methods}

A retrospective, observational, cross-sectional study of risk factor comparison problems was carried out. The prospectively-completed database of the cardiac surgery department was analyzed. Patients undergoing cardiac surgical intervention at the Instituto Cardiovascular de Buenos Aires, Argentina, between April 2018 and March 2019, and who had the APACHE II score determined at admission to the intensive care unit were included.

All patients aged $\geq 18$ years who underwent any of the following cardiovascular operations, either electively or as emergency: coronary artery bypass graft (CABG), valve operation (aortic, mitral, tricuspid or pulmonary), aortic arch or ascending aorta operation (aorto-aortic replacement, Bentall de Bono, Tyrone David or Yacoub technique), ventricular reconstruction operation, septal myectomy, congenital heart disease correction, Maze operation, heart transplantation, or combined cardiac interventions (two or more of the above-mentioned procedures), and with APACHE ॥ score calculated at intensive care admission, were included. Patients who had no APACHE II score within $24 \mathrm{~h}$ after admission to the intensive care unit or who expressed their refusal to participate were excluded.

The study independent variable was the APACHE II severity score, which was calculated at patient admission to the intensive care unit and was based upon different variables: age, rectal temperature, mean blood pressure, heart rate, respiratory rate, oxygenation (arterial oxygen pressure was used if inspired fraction of oxygen was $<50 \%$ or arterial alveolar oxygen gradient was $>50 \%$ ), blood $\mathrm{pH}$, sodium and potassium values, plasma creatinine, hematocrit, white blood cell count, Glasgow scale, and presence of chronic disease. The score interval could vary between 0 and 71 . Initially, it was evaluated as a continuous proportional variable. After obtaining the best cutoff value to predict the primary episode, it was also used as dichotomous variable for the multivariate analysis.

The dependent variables to be analyzed included the following:
1. In-hospital mortality: Mortality that occurred during the same hospitalization heart surgery was performed.

2. Low cardiac output (LCO): It was defined as a systolic blood pressure $<90 \mathrm{mmHg}$ with requirement of inotropics, along with a cardiac index $<2.2 \mathrm{~L} / \mathrm{min} / \mathrm{m}^{2}$ measured by thermodilution with Swan-Ganz catheter, and pulmonary wedge pressure $>18 \mathrm{mmHg}$.

3. Cerebrovascular accident (CVA): It was defined as new, transitory or permanent neurological focus, in relation to a new ischemic or hemorrhagic image on brain computed tomography.

4.Surgical bleeding: Post-operative hemorrhage with requirement of surgical measures for its control, either by excessive bleeding, hemothorax or cardiac tamponade.

5. Kidney failure requiring dialysis: Requirement of dialysis due to plasma creatinine increase 3 times over the baseline value together with oliguria or anuria, or due to the presence of emergency criteria: hyperkalemia or resistant acidosis, volume overload, uremic encephalitis or uremic pericarditis.

The study met all the requirements contained in the WHO code of ethics (Declaration of Helsinki) and was approved by the Clinical Research Committee and the Ethics Committee of the Institute. All patients signed the Habeas data.

\section{Statistical analysis}

Quantitative continuous variables parametric distribution was evaluated using the Kolmogorov-Smirnov test. Qualitative variables were expressed in proportions, while quantitative continuous variables were presented as means, with their respective standard deviations (SD) (in case of parametric distribution), or medians and interquartile range for non-parametric variables.

Student's t-test was used for the analysis of quantitative variables with parametric distribution, and Mann-Whitney's U-test was resorted to for non-parametrically distributed variables. The relationship between qualitative variables was defined based on Chi-square $\left(\chi^{2}\right)$ and Fisher tests.

The primary endpoint that was analyzed was in-hospital mortality. As secondary endpoints, the prevalence of LCO, CVA, surgical bleeding and the need for dialysis were evaluated.

To determine APACHE II calibration, the Hosmer-Lemeshow goodness-of-fit test was resorted to, which divided the population into deciles according to the expected probabilities of death, and a $\chi^{2}$ value was 
obtained from observed and expected frequencies. A $p>0.05$ was considered a good fit. A receiver operating characteristic $(\mathrm{ROC})$ curve was then used to define the APACHE II score differentiation capacity and to identify the best cutoff value for predicting in-hospital mortality.

A multivariate logistic regression model was carried out to adjust for various variables of interest. Odds ratios (ORs) were presented with their respective 95\% confidence intervals $(\mathrm{Cl})$ for the variables included in the models. A $5 \%$ two-tailed $\alpha$-error was considered as a statistically significant value $(p<0.05)$.

Statistical analyses were carried out with the IBM SPSS Statistics software, version 19.0.

\section{Results}

Five-hundred and fifty-nine patients who underwent cardiac surgery were analyzed. Of the total, $48 \%$ corresponded to CABG surgery, $24 \%$ to valve operation, $15 \%$ to combined procedures (valve operation related to CABG) and $13 \%$ to other type of intervention. Mean age was 67.1 years $(S D, 10)$ and most were males $(73.4 \%)$. As regards to cardiovascular risk factors, $76 \%$ of subjects were hypertensive, $24 \%$ were diabetics, $50 \%$ were smokers and $6 \%$ had a family-hereditary history of relevance. Regarding the presence of other comorbidities, $9 \%$ had a history of atrial fibrillation, and, $14 \%$, of moderate/severe ventricular dysfunction, $7 \%$ had undergone previous heart surgery, $6 \%$ had chronic lung disease, $3 \%$ had experienced a previous CVA and $8 \%$ had chronic kidney failure. As for the cardiac procedure that was practiced, in $53 \%$ of cases was a cardiopulmonary bypass pump used, and $25 \%$ were emergency procedures. APACHE II global mean score was 7.9 (SD, 4).

When baseline characteristics analysis was performed, dividing the population according to the best APACHE II cutoff value to predict in-hospital mortality, those who had higher APACHE II values were observed to be characterized for being significantly older, having a lower body mass index, and higher rates of chronic kidney failure, atrial fibrillation, previous heart surgery and left ventricular dysfunction (Table 1). The population with an APACHE II score $\geq 12$ also recorded a higher percentage of cardiopulmonary bypass pump utilization and a higher rate of emergency surgeries.

The prevalence of overall in-hospital mortality was $6.1 \%$. Regarding the secondary endpoints, a surgical bleeding rate of $9.3 \%$, a LCO rate of $12.7 \%$, a rate of CVA of $1.6 \%$ and a rate of kidney failure with dialysis requirement of $4.1 \%$ were observed.
Table 1. Baseline characteristics of the population divided according to the best APACHE II system cutoff value to predict in-hospital mortality (APACHE: 12)

\begin{tabular}{|c|c|c|c|c|c|}
\hline APACHE II & \multicolumn{2}{|c|}{$<12$} & \multicolumn{2}{|c|}{$\geq 12$} & \multirow[t]{2}{*}{ p } \\
\hline Variables & Mean & SD & Mean & SD & \\
\hline Age (years) & 65.9 & 11.0 & 70.0 & 10.6 & 0.0001 \\
\hline Female gender & $25.5 \%$ & & $32.8 \%$ & & 0.069 \\
\hline Weight (kg) & 82.4 & 14.8 & 75.9 & 12.9 & 0.0001 \\
\hline Height (cm) & 169.9 & 9.3 & 166.6 & 9.0 & 0.0001 \\
\hline HBP & $77.7 \%$ & & $73.1 \%$ & & 0.226 \\
\hline Smoking & $53.4 \%$ & & $44.1 \%$ & & 0.039 \\
\hline Diabetes & $24.1 \%$ & & $23.1 \%$ & & 0.792 \\
\hline HFH & $6.7 \%$ & & $5.4 \%$ & & 0.542 \\
\hline $\begin{array}{l}\text { Chronic kidney } \\
\text { failure }\end{array}$ & $5.6 \%$ & & $15.1 \%$ & & 0.0001 \\
\hline $\begin{array}{l}\text { Chronic lung } \\
\text { disease }\end{array}$ & $5.1 \%$ & & $8.6 \%$ & & 0.107 \\
\hline CVA & $2.7 \%$ & & $5.4 \%$ & & 0.106 \\
\hline Sinus rhythm & $96.5 \%$ & & $82.3 \%$ & & 0.0001 \\
\hline $\begin{array}{l}\text { Emergency } \\
\text { operation }\end{array}$ & $22.0 \%$ & & $37.1 \%$ & & 0.0001 \\
\hline CPB use & $49.8 \%$ & & $68.5 \%$ & & 0.0001 \\
\hline $\begin{array}{l}\text { Previous heart } \\
\text { surgery }\end{array}$ & $4.3 \%$ & & $12.4 \%$ & & 0.0001 \\
\hline Mod/Sev LVDF & $10.5 \%$ & & $20.4 \%$ & & 0.001 \\
\hline Apache II & 7.5 & 2.2 & 16.4 & 9.0 & 0.0001 \\
\hline
\end{tabular}

CPB: cardiopulmonary bypass pump; CVA: cerebrovascular accident; HBP: high blood pressure; HFH: hereditary/family history; Mod/SEV LVDF: moderate/severe left ventricular dysfunction; SD: standard deviation.

The Hosmer-Lemeshow goodness-of-fit test revealed a $p>0.05$, which implies a good calibration of the score for this population $\left(\chi^{2}=2.1\right.$; degree of freedom $=8$; $p=0.90)$. The APACHE II score also showed a very good differentiation capacity to predict in-hospital mortality, with an area under the ROC curve of $0.92(95 \%$ $\mathrm{Cl}, 0.88-0.96 ; p=0.0001$ ), with a sensitivity of $85 \%$ and specificity of $80 \%$ (Fig. 1). The best cut-off value of the score obtained by ROC curve to predict the primary final episode was 12. Patients with an APACHE II value $\geq 12$ had significantly higher in-hospital mortality, and higher incidence of LCO, CVA, surgical bleeding and need for dialysis (Table 2).

In a multivariate logistic regression model, in which adjustments were made for different variables (gender, 


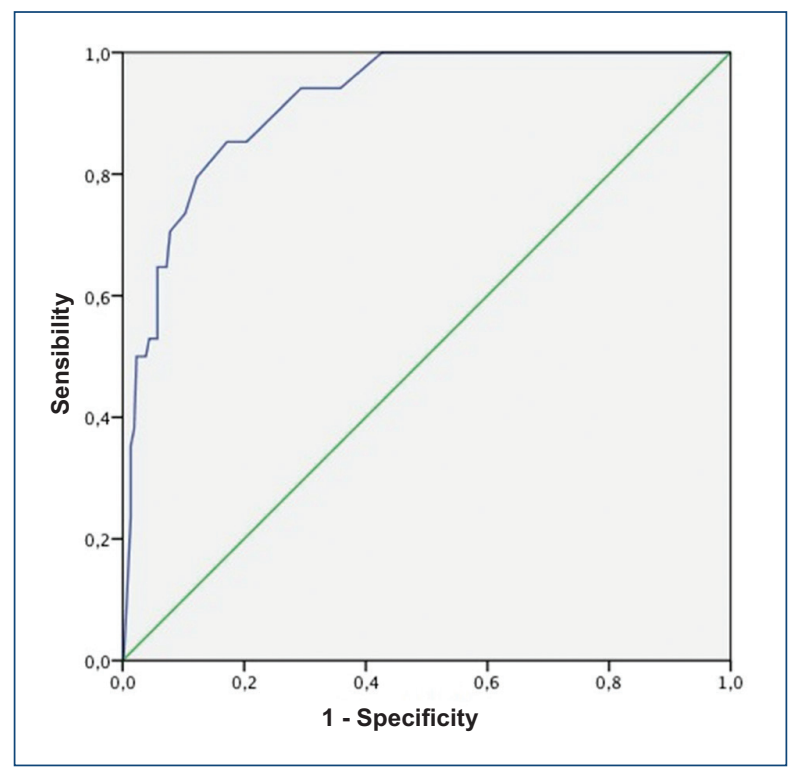

Figure 1. APACHE II scoring system ROC curve to predict in-hospital mortality. The APACHE II score had an area under the ROC curve of $0.92(95 \% \mathrm{Cl}, 0.88-0.96 ; p=0.0001)$, with a sensitivity of $85 \%$ and specificity of $80 \%$.

weight, smoking, history of CVA, chronic kidney failure, atrial fibrillation, prior heart operation, ventricular dysfunction, and use of cardiopulmonary bypass pump), each point of increase in the APACHE II score was significantly associated with a higher in-hospital mortality rate $(\mathrm{OR}, 1.14 ; 95 \% \mathrm{Cl}, 1.08-1.21 ; \mathrm{p}<0.0001$; Table 3). If the APACHE II variable is regarded as dichotomous based on the best cut-off value, having a score value $>12$ was observed to also be independently and significantly associated with a higher mortality rate $(\mathrm{OR}, 36.5 ; 95 \% \mathrm{Cl}, 8.2-161.6 ; \mathrm{p}<0.0001)$.

\section{Discussion}

Currently, predicting mortality in intensive care units is essential and a quality standard ${ }^{28,29}$. Patients who are in the post-operative period of a heart intervention are a special population, since the different predictive models that are commonly used in critical areas are not accurate, by virtue of their perioperative characteristics, and overestimate mortality. However, in this study, the APACHE II scoring system was shown to have adequate calibration and differentiation, with an excellent capacity to predict in-hospital mortality in patients who underwent cardiac procedures and were spending their post-operative period at the intensive care unit of a high-complexity cardiovascular center.
Table 2. Endpoints (primary and secondary) evaluated according to APACHE II value

\begin{tabular}{|l|c|c|c|c|}
\hline Episode & $\begin{array}{c}\text { APACHE } \\
<\mathbf{1 2}\end{array}$ & $\begin{array}{c}\text { APACHE } \\
\geq \mathbf{1 2}\end{array}$ & Total & $\mathbf{p}$ \\
\hline $\mathrm{N}$ & 373 & 186 & 559 & \\
\hline Mortality & $0.5 \%$ & $17.2 \%$ & $6.1 \%$ & $<0.0001$ \\
\hline Surgical bleeding & $1.9 \%$ & $24.2 \%$ & $9.3 \%$ & $<0.0001$ \\
\hline LCO & $0.3 \%$ & $37.6 \%$ & $12.7 \%$ & $<0.0001$ \\
\hline Dialysis & $0 \%$ & $12.4 \%$ & $4.1 \%$ & $<0.0001$ \\
\hline CVA & $0.8 \%$ & $3.2 \%$ & $1.6 \%$ & 0.032 \\
\hline
\end{tabular}

CVA: cerebrovascular accident; LCO: low cardiac output; n: number of patients.

Table 3. Multivariate logistic regression model to predict in-hospital mortality

\begin{tabular}{|l|c|c|c|c|}
\hline \multirow{2}{*}{ Variables } & \multirow{2}{*}{$\mathbf{P}$} & OR & \multicolumn{2}{|c|}{$15 \%$ CI } \\
\cline { 3 - 5 } & & & Lower & Upper \\
\hline Chronic kidney failure & 0.001 & 4.001 & 1.394 & 9.693 \\
\hline CPB & 0.024 & 5.016 & 1.242 & 20.251 \\
\hline Female gender & 0.003 & 4.223 & 1.632 & 10.930 \\
\hline Atrial fibrillation & 0.041 & 2.214 & 1.076 & 7.012 \\
\hline Previous CVA & 0.008 & 9.517 & 1.812 & 49.996 \\
\hline Smoking & 0.033 & 2.750 & 1.087 & 6.957 \\
\hline Previous heart surgery & 0.002 & 3.256 & 1.549 & 7.382 \\
\hline Mod/Sev LVDF & 0.0001 & 1.542 & 1.213 & 1.840 \\
\hline APACHE II (for each point) & 0.0001 & 1.141 & 1.076 & 1.211 \\
\hline
\end{tabular}

CVA: cerebrovascular accident; CPB: cardiopulmonary bypass pump; Mod/Sev LVDF: moderate/severe left ventricular dysfunction; OR: odds ratio.

In comparison with the works that evaluated the APACHE II score in general intensive care units from different countries, the evaluated population was different. Studies conducted in general intensive care units included younger patients, with a mean of 44 years in the study by Jacobs et al., 53 in that by Teik et al., and 58 years in the Canadian study by Wong et al ${ }^{22,23,26,27}$. In contrast, mean age of the population that was analyzed in this investigation was higher (67.1 years). Population comorbidities were substantially different since, in general critical care units, the patients had particularly a prior history of more renal and respiratory conditions (37 vs. 6\%), but a lower percentage left ventricular dysfunction ${ }^{23}$. On average, half the patients 
were admitted to the intensive care unit due to surgical alterations (mostly non-cardiac operations), while in this work all were in the post-operative period of a heart surgery procedure. Surgical procedures electivity was heterogeneous, in some cases similar to that of this study (25\% of emergency procedures) but, in some cases, the percentage was higher $(32 \%)^{22,26}$.

With regard to studies that assessed specific scores for subjects undergoing cardiac intervention, such as the Cardiac Surgery Score (CASUS) and the Post-Cardiac Surgery Score (POCAS), population baseline characteristics were similar to those of this work ${ }^{30-33}$. The main difference observed in Hekmat et al. original protocol was the inclusion of a higher percentage of isolated CABGs (62 vs. $48 \%$ ) and the lower number of valve procedures (16.5 vs. $24 \%)^{30}$.

In this work, APACHE II global mean was 7.9 (SD, 4). In comparison with other cohorts that analyzed general intensive care units, the value was low. The mean ranged from figures of 13 in Saudi Arabian cohorts, 14.2 in the USA, 14.7 in Japan, 16.5 in Canada and 17.9 in the United Kingdom to up to 20.1 in China $4,22-27$. This difference was probably due to the fact that patients who were in the post-operative period of a cardiac intervention had fewer comorbidities and better physiological score when admitted to the critical care unit and the risk was therefore mainly determined by the surgical intervention itself. However, when APACHE II mean is compared with studies that assessed only subjects with heart operations (as the study by Hekmat et al.), the mean was similar (8 vs. 7.9$)^{30}$.

The observed overall in-hospital mortality was $6.1 \%$. Conversely, in the analyses carried out in general intensive care units, the rate was significantly higher. It ranged from $16.9 \%$ in Japan, $19.7 \%$ in the United States, $24.8 \%$ in Canada, $27 \%$ in the United Kingdom, and $36 \%$ in China to up to $46 \%$ in Saudi Arabia ${ }^{4,22-27}$. Of course, the difference is explained because this study only included individuals undergoing heart surgery in a high-complexity cardiovascular center, with fewer comorbidities in comparison with those assisted in general intensive care units. Although the rate was low, the APACHE II scoring system value was also low, with adequate agreement between expected and actual mortality.

When analyzing studies that considered patients in the post-operative period of cardiac surgical procedures, mortality was similar to that recorded in this research: Badreldin et al. (5.8\%) and Exarchopoulos et al. $(6.0 \%)^{17,32}$. Nevertheless, differences were recognized in other groups, as in the study by Tamayo et al., which showed a higher mortality $(9.0 \%)^{33}$. Conversely, in their cohort, Hekmat et al. published a lower mortality than that of this protocol $(4.4 \%)^{30}$. This difference may be due to a lower complexity of the heart operations that were included by the German cohort since it had a higher number of CABGs and a lower rate of valve interventions.

As for the APACHE II system calibration through the Hosmer-Lemeshow test, it was very good in this population, with a $\chi^{2}$ of 2.2 , a significant $p$-value, and similar values to those of specific scores validated for cardiac operations $^{30-33}$.

APACHE II differentiation capacity in this study was excellent, with a ROC curve value of 0.92 being obtained $(95 \% \mathrm{Cl}, 0.88-0.96 ; p=0.0001)$. If compared with the ROC curves recorded in other protocols that used APACHE II in general intensive care units, it is observed to be the one with the largest area under the curve. In the original work by Knaus et al., the ROC curve value was 0.86 and was similar to that observed in the cohorts of China (0.89), Canada (0.86), the Unit-

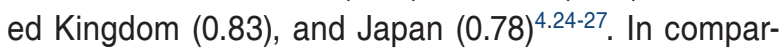
ison with specific models designed and validated for cardiac interventions, the ROC curve value of 0.92 that was obtained in this research is still the best (ICNARC score: 0.84; CASUS: 0.89 to 0.92; POCAS: 0.89; STS: 0.79; and EuroScore II: 0.78) ${ }^{13.30-35}$.

Regarding the best APACHE II scoring system cutoff value to predict in-hospital mortality, a value of 12 was obtained through the ROC curve in this study. This value is important since, in the current literature, there are few works that determine the best cutoff value of the score to predict episodes. One of them is the study by Parajuli et al., who compared APACHE systems II and IV in a general intensive care unit. The cutoff point with the best Youden index value was 17, which is somewhat higher than that obtained in said work ${ }^{36}$. Kuhn et al. also assessed the APACHE II score according to the best cutoff values at three cardiac surgery centers ${ }^{37}$. The APACHE II cutoff value that indicated a mortality higher than $50 \%$ was 28 , which is higher than that recorded in this protocol.

If secondary endpoints are analyzed, higher APACHE II values are identified to have also been related to a higher rate of CVA, surgical bleeding, LCO, and dialysis requirements. Either way, whether the relationship was independent and significant is not known, since the multivariate adjustment was carried out only for the primary final episode. When reviewing specialized publications, no works were found that predicted these events based on APACHE II. However, some studies using this system in patients on dialysis have been 
designed. Among them, Dobkin et al. evaluated the APACHE II score to identify cases of poor prognosis in a cohort of patients admitted to an intensive care unit and who were on dialysis ${ }^{38}$. Along the same lines, Van Bommel et al. studied the APACHE II system applicability in patients with acute kidney failure requiring dialysis in a surgical intensive care unit ${ }^{39}$. As a result, APACHE II, calculated within the first $24 \mathrm{~h}$, predicted mortality in that population.

In terms of clinical significance, the APACHE II classification is a simple model, validated in different international cohorts, with more than 30 years of use, and with physiological variables that are easy to calculate at patient bedside of any cardiovascular surgical unit. In addition, with the results of this study that demonstrated adequate calibration and differentiation in the post-operative period of subjects who underwent cardiac procedures, APACHE II might help stratify the risk of this special population and is therefore the risk model of choice.

The study has certain limitations that should be pointed out. First, it is a retrospective design, which increases the risk of bias. Second, the sample size is small in relation to internationally-evaluated risk models. Another limitation to consider is that it was a single-center work. Either way, it took place in a high-complexity monovalent cardiovascular center, with a high volume of heart operations.

\section{Conclusions}

In this study, the APACHE II scoring system was shown to be an independent predictor of in-hospital mortality in patients on the post-operative period of cardiac surgical interventions in the intensive care unit of a high-complexity cardiovascular center, after showing a very good calibration and excellent differentiation capacity. The APACHE II system was also related to a higher incidence of LCO, CVA, surgical bleeding and need for dialysis, and its use is therefore attractive to anticipate episodes in this special patient population.

\section{Funding}

This research has not received any specific grant from agencies of the public, commercial, or non-profit sectors.

\section{Conflicts of interests}

None.

\section{Ethical disclosures}

Protection of human and animal subjects: The authors declare that no experiments were performed on humans or animals for this research.

Confidentiality of data: The authors declare that they have followed the protocols of their work center on the publication of patient data.

Right to privacy and informed consent: The authors declare that no patient data are exposed in this article.

\section{References}

1. Jones $\mathrm{HJ}$, de Cossart L. Risk scoring in surgical patients. $\mathrm{Br} \mathrm{J}$ Surg. 1999;86:149-57

2. Rapsang AG, Shyam DC. Scoring systems in the intensive care unit: a compendium. Indian Journal of Critical Care Medicine: Peer-reviewed (Official Publication of Indian Society of Critical Care Medicine, India). 2014;18:220-8.

3. Sirio CA, Knaus WA. Application of prognostic scoring in adult intensive care. Curr Opin Anaesthesiol. 1990;3:241-4.

4. Knaus WA, Draper EA, Wagner DP, Zimmerman JE. APACHE II: a severity of disease classification system. Crit Care Med. 1985:13(10):818-29.

5. Le Gall JR, Lemeshow S, Saulnier F. A new simplified acute physiology score (SAPS II) based on a European/North American multicenter study. JAMA. 1993;270(24):2957-63.

6. Moreno RP, Metnitz PG, Almeida E, Jordan B, Bauer P, Campor RA et al. SAPS 3: from evaluation of the patient to evaluation of the intensive care unit. Part 2: development of a prognostic model for hospital mortality at ICU admission. Intensive Care Med. 2005:31:1345-55.

7. Lemeshow S, Teres D, Klar J, Avrunin JS, Gehlbach SH, Papoport J. Mortality probability models (MPM II) based on an international cohort of intensive care patients. JAMA 1993;270:2478-86.

8. Lemeshow S, Le Gall JR. Modeling the severity of illness of ICU patients. A systems update. JAMA. 1994;272:1049-55.

9. Ferreira FL, Bota DP, Bross A Mélot C, Vincent JL. Serial evaluation of the SOFA score to predict outcome in critically ill patients. JAMA. 2001;286(14):1754-8.

10. Ceriani R, Mazzoni M, Bortone F, Gandini S, Solinas C, Susini G, et al. Application of the sequential organ failure assessment score to cardiac surgical patients. Chest. 2003;123(4):1229-39.

11. Marshall JC, Cook DJ, Christou NV, Bernard GR, Sprung CL, Sibbald WJ. Multiple organ dysfunction score: a reliable descriptor of a complex clinical outcome. Crit Care Med. 1995;23(10):1638-52.

12. Turner JS, Morgan CJ, Thakrar B, Pepper JR. Difficulties in predicting outcome in cardiac surgery patients. Crit Care Med. 1995;23(11):1843-50.

13. Nashef SA, Roques F, Sharples LD, Nilsson J, Smith C, Goldstone AR, et al. EuroSCORE II. Eur J Cardiothorac Surg. 2012;41:734-44.

14. Anderson RP. First publications from the Society of Thoracic Surgeons National Database. Ann Thorac Surg. 1994;57:6-7.

15. Ranucci M, De Toffol B, Isgró G, Romitti F, Conti D, Vicentini M. Hyperlactatemia during cardiopulmonary bypass: determinants and impact on postoperative outcome. Crit Care. 2006;10(6):167.

16. Demers $P$, Elkouri S, Martineau R, Couturier A, Cartier R. Outcome with high blood lactate levels during cardiopulmonary bypass in adult cardiac surgery. Ann Thorac Surg. 2000;70:2082-6.

17. Badreldin A, Doerr F, Elsobky S, Brehm BR, ABul-dahab M, Lehmann T, et al. Mortality prediction after cardiac surgery: blood lactate is indispensible. Thorac Cardiovasc Surg. 2013;61(8):708-17.

18. Magilligan DJ, Teasdall R, Eisinminger R, Peterson E. Mixed venous oxygen saturation as a predictor of cardiac output in the postoperative cardiac surgical patient. Ann Thorac Surg. 1987;44 (3):260-2.

19. Holm J, Håkanson E, Vánky F, Svedjeholm R. Mixed venous oxygen saturation predicts short- and long-term outcome after coronary artery bypass grafting surgery: a retrospective cohort analysis. Br J Anaesth. 2011;107(3):344-50.

20. Ranucci M, Ballota A, Castelvecchio S, Baryshnikova E, Brozzi S, Boncilli A, et al. Intensive care unit admission parameters improve the accuracy of operative mortality predictive models in cardiac surgery. PLoS One. 2010;5(10):e13551.

21. Knaus WA, Zimmerman JE, Wagner DP, Draper EA, Lawrence DE. APACHE - acute physiology and chronic health evaluation: a physiologically based classification system. Crit Care Med. 1981;9(8):591-7.

22. Jacobs S, Chang RWS, Lee B. One year's experience with the APACHE II severity of disease classification system in a general intensive care unit. Anaesthesia. 1987;42:738-44. 
23. Jacobs S, Chang RWS, Lee B, Lee B. Audit of intensive care: a 30 month experience using the APACHE II severity of disease classification system. Int Care Med. 1988;14:566-74.

24. Sirio CA, Tajimi K, Knaus WA, Wagner DP, Hirasawa $H$, Sakanishi N, K et al. An initial comparison of intensive care in Japan and the United States. Crit Care Med. 1992;20:1207-15.

25. Rowan KM, Kerr JH, Major E, McPherson K, Shorta A, Vessey MP. Intensive care society's APACHE II study in Britain and Ireland. II: outcome comparisons of intensive careunits after adjustment for case mix by the American APACHE II method. BMJ. 1993;307(6910):977-81.

26. Teik E, Hutchinson MB, Short S, Buckley T, Lin E, Leung D. Verification of the acute physiology and chronic health evaluation scoring system in Hong Kong intensive care unit. Crit Care Med. 1993;21(5):698-705.

27. Wong DT, Crofts SL, Gómez M, McGuire GP, Byrick RJ. Evaluation of predictive ability of APACHE II system and hospital outcome in Canadian intensive care unit patients. Crit Care Med. 1995;23(7):1177-83.

28. Chassin MR, Galvin RW. The urgent need to improve health care quality. Institute of Medicine National Roundtable on Health Care Quality. JAMA. 1998;280:1000-5.

29. Blumenthal D, Epstein AM. Quality of health care. Part 6: the role of physicians in the future of quality management. $\mathrm{N}$ Engl $\mathrm{J}$ Med. 1996;335:1328-31.

30. Hekmat K, Kroener A, Stuetzer H, Schwinger RH, Kampe S, Bennink GB et al. Daily assessment of organ dysfunction and survival in intensive care unit cardiac surgical patients. Ann Thorac Surg. 2005;79(5):1555-62.

31. Hekmat K, Doerr F, Kroener A, Heldwein M, Bossert T, Badreldin AM, et al. Prediction of mortality in intensive care unit cardiac surgical patients. Eur J Cardiothorac Surg. 2010;38(1):104-9.
32. Exarchopoulos T, Charitidou E, Dedeilias P, Charitos C, Routsi C. Scoring systems for outcome prediction in a cardiac surgical intensive care unit: a comparative study. Am J Crit Care. 2015;24(4):327-34.

33. Tamayo E, Fierro I, Bustamante-Munguira J, Heredia-Rodríguez M, Jorge-Monjas $\mathrm{P}$, Maroto L, et al. Development of the post cardiac surgery (POCAS) prognostic score. Crit Care. 2013;17(5):R209.

34. Ariyaratnam P, Loubani M, Biddulph J, Moore J, Richards N, Chaudhry M, et al. Validation of the Intensive Care National Audit and Research Centre Scoring System in a UK adult cardiac surgery population. J Cardiothorac Vasc Anesth. 2015;29(3):565-9.

35. O'Brien SM, Shahian DM, Filardo G, Ferraris VA, Haan CK, Rich JB, et al. The Society of Thoracic Surgeons 2008 cardiac surgery risk models: part 2--isolated valve surgery. Ann Thorac Surg. 2009;88(1):23-42.

36. Parajuli BD, Shreshta GS, Pradhan B, Amatya R. Comparison of acute physiology and chronic health evaluation II and acute physiology and chronic health evaluation IV to predict intensive care unit mortality. Indian J Crit Care Med. 2015;19(2):87-91.

37. Kuhn C, Muller-Werdan U, Schmitt DV, Lange H, Pilz G, Kreuzer E, et al. Improved outcome of APACHE II score-defined escalating systemic inflammatory response syndrome in patients post cardiac surgery in 1996 compared to 1988-1990: the ESSICS-study pilot project. Eur J Cardiothorac Surg. 2000;17(1):30-7.

38. Dobkin J, Cutler R. Use of APACHE II classification to evaluate outcome of patients receiving hemodialysis in an intensive care unit. West $\mathrm{J}$ Med. 1988;149(5):547-50.

39. Van Bommel EF, Bouvy ND, Hop WC, Bruining HA, Weimar W. Use of APACHE II classification to evaluate outcome and response to therapy in acute renal failure patients in a surgical intensive care unit. Renal Failure. 1995;17(6):731-42. 